\title{
ИНИЦИАТИВА «ПОЯС - ПУТЬ»: ПРИЧИНЫ ВЫДВИЖЕНИЯ И АКТИВИЗАЦИЯ ГУМАНИТАРНЫХ НАПРАВЛЕНИЙ РЕАЛИЗАЦИИ
}

\author{
И. А. ЧУВИЛОВ \\ Белорусский государственный экономический университет \\ Минск, Республика Беларусь
}

\begin{abstract}
Аннотация. Настоящее исследование приводит аргументы, доказывающие преемственность между Великим Шелковым путем и инициативой «Пояс путь», рассматривает роль данной инициативы в формировании новой политической модели международного устройства. Автор аргументирует важность инициативы «Пояс - путь» для современного внешнеполитического курса Китая, оценивает перспективы развития данной инициативы. Новизна настоящей работы заключается в рассмотрении взаимосвязей между Великим Шелковым путем, инициативой «Пояс - путь», а также трибутарной системой имперского Китая и идеей о построении сообщества единой судьбы человечества; введении в научный оборот понятия гуманитарных стратегий реализации инициативы «Пояс - путь». В результате исследования автор приходит к следующим выводам:
\end{abstract}

1) инициатива «Пояс - путь» явилась смелой попыткой политических элит Китая по возрождению могущества китайского государства, основанной на успешном опыте взаимодействия с международным сообществом в эпоху Великого Шелкового пути;

2) в способах реализации инициативы «Пояс - путь» наряду с экономическими факторами и направлениями необходимо выделить также и гуманитарные стратегии, которые к концу второго десятилетия XXI в. начинают приобретать все большее значение.

Результаты данного исследования могут быть использованы для дальнейшего изучения инициативы «Пояс - путь», научного осмысления с позиций политической и исторической наук внешней политики современного Китая.

Ключевые слова: Китайская Народная Республика; Великий Шелковый путь; инициатива «Пояс - путь»; внешняя политика Китая; трибутарная система; сообщество единой судьбы человечества; гуманитарные стратегии; культура; искусство; образование; хуацяо.

Образец цитирования: Чувилов И. А. Инициатива «Пояс - путь»: причины выдвижения и активизация гуманитарных направлений реализации // Актуальные проблемы международных отношений и глобального развития: сб. науч. ст. Минск, 2021. Вып. 9. С. 276-288. https://doi.org/10.33581/2311-9470-2021-9-276288 
Введение. Инициатива «Пояс - путь» (ИПП) стремительно привлекает внимание как акторов международной системы, так и исследователей внешней политики и международных отношений. Каждое государство, заинтересованное в выстраивании продуктивных отношений с Китаем, нуждается в грамотном реагировании на его внешнеполитические шаги. В настоящее время важнейшим проектом Китая без сомнений можно назвать инициативу «Пояс - путь». Актуальность ее изучения обусловлена прогрессивным увеличением влияния Китая в современной международной политике.

Методология исследования. Объект исследования - инициатива «Пояс - путь». Предмет исследования - особенности реализации Китаем инициативы «Пояс - путь» в историческом, политическом и гуманитарном контекстах. Цель исследования - выявить основные направления реализации инициативы «Пояс - путь». Для достижения заявленной цели поставлены задачи:

1. Определить основные причины из истории Китая, повлекшие инициирование ИПП, а также главные направления ее реализации.

2. Доказать наличие и значимость гуманитарных стратегий при реализации ИПП.

Для решения указанных задач в настоящем исследовании применялись историко-ретроспективный и компаративный методы, методы политической науки, ряд общенаучных методов.

Обзор литературы по теме исследования. В Республике Беларусь вопросами изучения внешней политики Китая, а также инициативы «Пояс - путь» занимаются как признанные (А. М. Байчоров, Ю. И. Малевич, М. В. Данилович, О. П. Рубо и др.), так и молодые перспективные исследователи. Среди иностранных исследователей, которые посвятили свои научные труды осмыслению инициативы «Пояс - путь», можно назвать Цзэн Линляна (КНР), Чжан Вэйвэя (КНР), Янь Сюэтуна (КНР), А. А. Кирееву (РФ), И. Г. Чубарова (РФ), М. Глянца (США) и др.

Результаты исследования. Китай имеет долгую историю своего развития не только как государства, но и как нации, цивилизации. Отмечается, что приблизительно миллион семьсот тысяч лет назад в провинции Юньнань уезде Юаньмоу уже жили предки современных китайцев. Около 2070 лет до н.э. возникла первая в истории Китая ди- 
настии Ся ${ }^{1}$. История китайской нации включает в себя периоды могущества, всецелого благополучия и величия, но также и времена застоя, бедности и внутреннего раздора. Подконтрольные Китаю территории могли значительно увеличиваться, а затем быть отобраны или отвоеваны противником. При этом китайцы всегда заботились о своем государстве и смогли выработать принципы сохранения национальной идентичности, традиций и управления отношениями с соседями.

Профессор истории и международных отношений Йельского университета Одд Арне Вестад отмечает, что «решающей составляющей китайского образа мышления ... считается ощущение своего центрального положения в мире» [1, с. 16]. Само наименование «Китай» на китайском языке («чжунго») буквально означает «Срединное государство», что отражает восприятие китайцами своего центрального положения в мире. Китай считал свою культуру, принцип государственного устройства образцовыми и не требующими значительной корректировки. В результате такого подхода китайцами были выработаны различные принципы взаимодействия с окружающими его народами. Ярким примером является трибутарная система (автором данного термина является американский синолог Дж. Фэрбэнк), в рамках которой имперский Китай времен династий Мин и Цин выстраивал отношения со своими соседями, основываясь на принципе своей центральности и верховенства китайской силы и власти. Дж. Фэрбэнк отмечал, что трибутарная система явилась результатом культурного превосходства китайцев, использовалась правителями Китая для политических целей самообороны, имела экономический базис и служила средством для китайской дипломатии [2, с. 137].

Однако задолго до становления трибутарной системы Китай начал взаимодействовать с миром благодаря Великому Шелковому пути. Великий Шелковый путь, проложенный во втором столетии до н.э., имел многовековую историю, являлся важнейшей платформой древнего Китая по расширению своего влияния и укреплению экономических и культурных связей с государствами Евразии и Африки, именно он стал прообразом современной китайской инициативы

\footnotetext{
${ }^{1}$ 中国历史常识: 中俄对照 / 中华人民共和国国务院侨务办公室, 国家汉语国际推广领导小组 办公室编 - 北京: 华语教学出版社, 2006. 259 页 = Общие знания по истории Китая: на китайском и русском языках / Составлено Управлением по делам зарубежного Китая Государственного совета Китайской Народной Республики и Управлением ведущей группы по международному продвижению китайского языка. Пекин: Издательство для преподавания китайского языка, 2006. 259 с. (на кит.яз.)
} 
«Пояс - путь». Своеобразным годом рождения Великого Шелкового пути считается 138 год до н.э., когда китайский путешественник Чжан Цянь по поручению императора У-ди отправился за пределы Великой китайской стены в западные земли. Спустя 10 лет он вернулся на родину, обвестив о том, насколько велик мир за пределами Китая. Путешественник был поражен красотой и величием лошадей из Ферганской долины и предложил У-ди организовать обмен китайского шелка на лошадей из этой долины. Таким образом Цжан Цянь способствовал установлению экономических связей между Китаем и странами Азии. С тех пор торговые маршруты стали важной составляющей экономического развития Китая. «Более 2100 лет назад в эпоху китайской династии Хань известный в истории Китая дипломат Чжан Цянь, дважды посетив с мирной и дружественной миссией Среднюю Азию, открыл двери для контактов между Китаем и среднеазиатскими странами, и тем самым проложил Великий Шелковый путь, протянувшийся с Востока на Запад и соединяющий Европу с Азией», - сказал Си Цзиньпин, выступая 7 сентября 2013 г. в Астане, когда впервые широкой публике было объявлено о новой инициативе Китая [3, с. 187]. Председатель КНР намеренно начал свое выступление с упоминания Великого Шелкового пути, дабы показать преемственность в исторических традициях своей нации и взаимосвязь этих инициатив. ИПП позиционируется как продолжатель великих достижений древней империи, которая в современном ее состоянии именуется Китайская Народная Республика. Получивший широкое признание в научных кругах Китая и за рубежом профессор Цзэн Линлян высказывал точку зрения о том, что ИПП призвана нести дух древнего Шелкового пути и справиться с возникшими международными политическими, экономическими и социальными проблемами в мире глобализации и глобального управления [4, с. 518].

В июне 2014 г. на церемонии открытия 6-й конференции Форума сотрудничества между Китаем и арабскими странами на уровне министров, председатель КНР в своей речи вновь упомянул Великий Шелковый путь и напомнил о том, что «на протяжении тысячелетий из поколения в поколения через Шелковый путь передавался дух мира и сотрудничества, открытости и инклюзивности, учебы друг у друга, взаимной выгоды и взаимного выигрыша» [3, с. 425]. «Развивать дух Шелкового пути, - считает Си Цзиньпин, - означает провозглашать мир и диалог» [там же, с. 428]. 
«Золотым веком» Великого Шелкового пути считается эпоха правления династии Тан (618 - 907 гг. н.э.), когда единственная женщина - императрица в истории Китая У Цзэтянь добилась того, чтобы Шелковый путь приобрел новый стимул в развитии. К сожалению, он к XV в. утратил свою значимость и остался лишь в памяти людей как былое великое взаимодействие народов.

В конце XX в. интерес среди международного сообщества к Великому Шелковому пути возник вновь во многом благодаря реализации политики реформ и открытости в КНР. В 1988 г. ЮНЕСКО начала проект «Интегральное исследование Шелкового пути - пути диалога», нацеленный на изучение взаимодействия между цивилизациями Востока и Запада ${ }^{2}$. Впоследствии при поддержке ЮНЕСКО было организовано несколько крупных проектов, связанных с древним Шелковым путем. На 38-й сессии комитета Всемирного наследия при ЮНЕСКО в 2014 г. Великий Шелковый путь был включен в список Всемирного наследия ЮНЕСКО, что в лишний раз подтвердило культурно-историческую ценность этого торгового маршрута ${ }^{3}$.

Идеи возрождения Великого Шелкового пути высказывались неоднократно. Акт о стратегии Шелкового пути 1999 г. в США призывал к оказанию гуманитарной, экономической и другой помощи странам Южного Кавказа и Центральной Азии ${ }^{4}$ В исследовании профессора А. М. Байчорова также отмечается заинтересованность в возрождении Шелкового пути у Турции, которая представила собственный «Проект Шелкового пути» в 2008 г. [5, с. 6]. Государственный секретарь США Х. Клинтон летом 2011 г. в своей речи в г. Ченнаи (штат Тамилнад в Индии) изложила стратегию нового Шелкового пути, призывая к тому, чтобы совместными усилиями «создавать новый Шелковый путь» ${ }^{5}$. Однако всеобъемлющее воплощение идея возрождения Шелкового пути нашла лишь в Китае.

На сегодняшний день инициатива «Пояс - путь» стала одним из приоритетных направлений внешней политики Китая. У каждого гос-

\footnotetext{
${ }^{2}$ Who are we? // Youth Eyes on the Silk Roads: International Photo Contest [Electronic resource]. URL: https://unescosilkroadphotocontest.org/en/node/4 (accessed: 14.10.2020).

3 Великий шелковый путь включен в список Всемирного наследия ЮНЕСКО // ТАСС. 22.06.2014. [Электронный pecypc]. URL: https://tass.ru/kultura/1272504 (дата обращения: 14.10.2020).

${ }^{4}$ H.R. 1152 - Silk Road Strategy Act of 1999 // Congress.gov [Electronic resource]. URL: https:// www.congress.gov/bill/106th-congress/house-bill/1152 (accessed: 11.02.2021).

${ }^{5}$ Remarks on India and the United States: A Vision for the 21st Century // U.S. Department of State [Electronic resource]. URL: https://2009-2017.state.gov/secretary/20092013clinton/rm/2011/07/ 168840.htm (accessed: 02.02.2021).
} 
ударства были свои причины присоединиться к данной инициативе: для одних - это было желание получения экономических преференций или гарантий безопасности, для других - боязнь потерять важного партнера, отношения с которым, однако, не всегда стабильны, для третьих - страх остаться одному в той конкурентной борьбе, гонку в которой не выиграть в одиночку; для четвертых - сразу несколько причин были решающими.

Государства, которые стремятся стать членом определенной международной организации, зачастую привлечены желанием получения выгод экономического или же политического характера. Однако ИПП официально не является структурно учрежденной международной институцией, поэтому выражение «страна - член ИПП» весьма формально, более удачным видится понятие «страна - участник». Такая довольно размытая институциональная организация ИПП позволяет Китаю легко маневрировать и более свободно действовать в отношениях с другими акторами мировой политики.

Китай как опорный центр данной инициативы собирает вокруг себя единомышленников, готовых вместе преследовать взаимовыгодные цели. В то же время такие цели не всегда одновременно выгодны и Китаю, и его соратникам по ИПП. Китай выступает в качестве донора инвестиций, экономических вливаний и кредитов. У партнеров Китая обычно есть право выбора: соглашаться на выдвигаемые им условия сотрудничества, пересмотреть ли их, либо в крайнем случае решительно отказаться. Китаю ИПП, на наш взгляд, представляется намного выгоднее, чем его партнерам по данной инициативе. Первейшая цель Китая, первопричина выдвижения собственно Экономического пояса Шелкового пути и Морского Шелкового пути XXI в., а затем их слияние в ИПП, последующее определение цели построения сообщества единой судьбы человечества, реализация «китайской мечты» - это желание и даже рвение вернуть себе то, что было отторгнуто у него во второй половине XIX - начале XX вв. - власть, влияние, величие. Это мечта осуществить предполагаемое предсказание Конфуция о том, что великий китайский дракон проснется, и от ударов его хвоста содрогнется весь мир.

При этом не стоит относиться к подобной мечте Китая как к ревизионистской: страна всегда считала себя центром мира, само название страны на китайском языке подчеркивает такое отношение китайцев к своему государству. Китай не стремится подчинить весь мир себе, не желает стать его властелином, руководство государства по- 
просту считает себя более компетентным в вопросах управления. Истеблишмент (при этом данный факт распространяется как на древних императоров, так и на современных лидеров КПК) страны предполагает, что именно Китаю присуща способность грамотного управления миром. Отсюда и проистекает стремление построения сообщества единой судьбы человечества как конечной цели Китая в его внешнеполитических целях, где в настоящий момент важнейшим элементом стала инициатива «Пояс - путь».

Особенностью ИПП, проявившейся в процессе ее реализации, стала возросшая роль гуманитарной сферы. В настоящем исследовании под гуманитарной сферой во внешней политике Китая подразумевается область взаимодействия Китая с международным сообществом в сфере культуры, искусства, образования (в том числе науки), а также деятельность китайских соотечественников за рубежом (хуацяо). Необходимость обращения Китая к более тесному контакту с государствами вдоль «Пояса - пути» в гуманитарной сфере обусловлена неоднозначным и недоверительным отношением некоторых государств к экономическим проектам и предложениям КНР.

Так, в докладе Всемирного банка 2019 г., озаглавленном «Экономика "Одного пояса, одного пути": возможности и риски транспортных коридоров», приводятся аналитические данные об экономической стороне ИПП, анализируются перспективы развития инициативы и выгоды и риски от нее для определенных аспектов мировой и национальной экономик. Авторы данного документа приходят к выводам, что ИПП «несет в себе риски, обычные для крупных инфраструктурных проектов» ${ }^{6}$. Отмечается, что «усугублению этих рисков может способствовать недостаточная прозрачность и открытость инициативы, а также слабость экономических основ и управления в некоторых странах - участницах» ИП ${ }^{7}$. А. М. Байчоров подчеркивает, что инициативе «Пояс - путь» также еще не удалось устранить опасения других стран по поводу международной экономической и политической экспансии Китая [5, с. 7]. Полномасштабное воплощение в жизнь ИПП и сообщества единой судьбы человечества, по мнению кандидата политических наук А. А. Киреевой, «может привести

\footnotetext{
6 Экономика «Одного пояса, одного пути»: возможности и риски транспортных коридоров // Open knowledge World Bank Group [Электронный pecypc]. URL: https://openknowledge. worldbank.org/bitstream/handle/10986/31878/211392RU.pdf?sequence=12\&isAllowed=y （дата обращения: 11.03.2021).

${ }^{7}$ Там же
} 
к формированию ассиметричной экономической зависимости стран от Китая» [6, с. 72].

Инициатива «Пояс - путь» из инфраструктурной цепи транспортных коридоров превращается в многогранную, массивную международную институцию, которая, несмотря на отсутствие формальных учредительных документов, обладает признаками международной организации: документально обеспечение («Видение и действие, направленные на продвижение совместного строительства Экономического пояса Шелкового пути и Морского Шелкового пути XXI в.» ${ }^{8}$, «План действий Министерства культуры по развитию культуры в рамках ИПП (2016-2020)» ${ }^{9}$, меморандумы о взаимопонимании и сотрудничестве в рамках инициативы «Пояс - путь» между Китаем и правительствами других государств ${ }^{10}$ ), международным признанием (проведены уже 2 форума ИПП ${ }^{11}$, данная инициатива упоминается в документах Организации Объединенных Наций и иных организаций $^{12}$ ). Особенностью ИПП, отличающей ее от обычных международных экономически направленных инициатив, является стратегичность и глобальная направленность китайской внешней политики.

Китайскому правительству не выгодно выстраивать исключительно экономические взаимоотношения в рамках настолько масштабной инициативы. Еще в своей речи в Казахстане в 2013 г. Си Цзиньпин указал на гуманитарный аспект Экономического пояса Шелкового пути (ЭПШП), пояснив, что для успешности экономической составляющей новой инициативы «необходимо получать поддержку со стороны народов разных стран, активизировать друже-

\footnotetext{
${ }^{8}$ Видение и действие, направленные на продвижение совместного строительства «Экономического пояса Шелкового пути» и «Морского Шелкового пути 21-го века» // Посольство Китайской Народной Республики в Российской Федерации. 23.04.2015 [Электронный ресурс]. URL: http://ru.china-embassy.org/rus/ggl/t1257296.htm (дата обращения: 16.03.2021).

9 文化部“一带一路”文化发展行动计划 (2016-2020 年) // 中华人民共和国国务院新闻办公室 [电子资源]. URL: http://www.scio.gov.cn/xwfbh/xwbfbh/wqfbh/35861/36653/xgzc36659/Document/ 1551344/1551344.htm (accessed: 16.03.2021).

${ }^{10}$ Cooperation agreements and MoUs under the Belt and Road Initiative // Belt and Road Initiative [Electronic resource]. URL: https://www.beltroad-initiative.com/memorundum-of-understandingbelt-and-road-initiative/ (accessed: 16.03.2021).

${ }^{11}$ The second Belt and Road Forum for international cooperation [Electronic resource]. URL: http://www.beltandroadforum.org/english/ (accessed: 16.03.2021).

${ }^{12}$ UN Agencies Belt and Road Initiative Involvement // UN Environment programme Document Repository [Electronic resource]. URL: https://wedocs.unep.org/bitstream/handle/20.500.11822/ 26318/UN\%20Agencies\%20BRI\%20Involvement\%2002\%20\%2801\%20Oct\%202018\%29.pdf?seq uence $=17 \&$ isAllowed $=y$ (accessed: 15.03.2021).
} 
ственные контакты между ними, усиливать взаимное понимание, традиционную дружбу» [3, с. 392].

Посол КНР в Российской Федерации Чжан Ханьхуэй указал на важность гуманитарной стороны инициативы «Пояс - путь», которая «своим главным направлением и основой считает экономическое сотрудничество, а важнейшей поддержкой - гуманитарные обмены» ${ }^{13}$.

И. Г. Чубаров (в соавторстве с Д. Б. Калашниковым) высказывает предположение о формировании Китаем «гуманитарной инфраструктуры» в рамках взаимодействия с зарубежными государствами, в том числе вдоль «Пояса - пути», указывает на то, что цель наращивания «мягкой силы» Китая - «повышение эффективности внешнеэкономической деятельности» [7, с. 29].

Гуманитарная составляющая инициативы «Пояс - путь», как, собственно, и гуманитарные стратегии ее реализации, опирается на привлечение инструментов «мягкой силы». Концепт «мягкой силы» был досконально изложен политологом Дж. Наем, который рассматривал «мягкую силу» как «способность получать желаемое за счет привлекательности, а не за счет принуждения или выплат», отмечая, что «мягкая сила» возникает благодаря «привлекательности культуры, политических идеалов и политики страны» [8, с. 10]. Развила и критически дополнила концепцию Дж. Ная профессор О. Г. Леонова, указывающая на то, что ««мягкая сила» - это совокупность гуманитарных ресурсов страны (государства), которые можно реализовать с помощью определенных технологий» [9, с. 88].

Хуан Линтань, доцент факультета марксизма Хунаньского университета, считает, что «стратегическая концепция инициативы «Пояс - путь» воплощает «мягкую силу» культуры» [10, с. 80]. ИПП является важной частью китайской мечты о великом обновлении китайской нации и ставит перед собой цель создать имидж Китая как цивилизованной (вэньмин) и ответственной державы на международной арене, при чем международный имидж, в конечном итоге, - это культурной образ и авторитет Китая [Там же, с. 82].

Профессор Фань Чжоу утверждает, что, с тех пор как Дж. Най предложил концепцию «мягкой силы», она стала одним из важных индикаторов для измерения всеобъемлющей национальной мощи и международного влияния страны [11, с. 44]. Согласно его точке зре-

13 «Один пояс, один путь»: открыть дорогу взаимному выигрышу // Посольство Китайской Народной Республики в Российской Федерации. 16.01.2021 [Электронный ресурc]. URL: http://ru.china-embassy.org/rus/zgxw/t1846717.htm (дата обращения: 16.03.2021). 
ния, в настоящее время Китай переживает важный период перехода от экономической глобализации к культурной, и инициатива «Пояс путь» возникла в соответствии с требованиями времени и стала важной стратегией Китая по отстаиванию новой модели международных отношений [Там же, с. 45].

Гуманитарная составляющая ИПП, которую можно рассматривать с позиций гуманитарных стратегий ее реализации, позволяет сохранить дееспособность инициативы при негативном опыте взаимодействия в экономической сфере. К собственно гуманитарным стратегиям ИПП относятся взаимодействие КНР с странами вдоль «Пояса и пути» в таких областях, как искусство и культура, образование (наука, деятельность Институтов Конфуция), а также разноплановый и зачастую целенаправленный процесс взаимодействия проживающих за пределами Китая этнических китайцев (хуацяо) с населением и структурами стран, в которых они пребывают на долго- и краткосрочной основе.

Выводы. Инициатива «Пояс - путь» - это в первую очередь результат накопленного за тысячелетия развития китайской нации опыта, воплотившегося в соответствии с реалиями XXI в. в многоаспектную стратегическую программу упрочения позиций КНР в системе международных отношений. Главным прообразом для ИПП выступил зарекомендовавший себя с положительной стороны исторический Великий Шелковый путь вкупе с трибутарной системой имперского Китая. В процессе развития ИПП наблюдается тенденция к трансформации данной инициативы из преимущественно экономической в экономико-гуманитарную. В результате чего возрастает роль культуры, искусства, образования и хуацяо в осуществлении гуманитарных аспектов инициативы «Пояс - путь», феномен которых ввиду своей значимости и целостности может быть рассмотрен в качестве особой стратегии реализации данной инициативы. Гуманитарные стратегии ИПП, основывающиеся на внедрении инструментов и практик «мягкой силы», нельзя рассматривать как полностью заменяющие экономические аспекты инициативы: несмотря на некоторые неудачи в торгово-экономическом, инфраструктурном и инвестиционном направлениях, экономика выступает основой ИПП, при этом гуманитарные стратегии становятся все более значительной поддержкой для инициативы «Пояс - путь». 


\title{
Библиографические ссылки
}

1. Вестад О. А. Беспокойная империя. Китай и мир с 1750 года / пер. с англ. С.А. Белоусова. Москва: ЗАО Издательство Центрполиграф. 2014. 639 с.

2. Fairbank J. K., Teng S. Y. On The Ch'ing Tributary System // Harvard Journal of Asiatic Studies. 1941. Vol. 6. № 2. P. 135-246.

3. Си Цз. О государственном управлении. Том 1. Пекин: Изд-во лит. на иностр. яз. 2018. $654 \mathrm{c}$.

4. Zeng L. Conceptual analysis of China's Belt and Road initiative: a road towards a regional community of common destiny // Chinese Journal of international law. 2016. Vol. 15. № 3. Pp. 517-541.

5. Байчоров А. М. Инициатива «Один пояс - один путь»: стратегические и тактические задачи // Белорусско-российские отношения на современном этапе: состояние и перспективы развития: материалы круглых столов / Белорус. гос. ун-т ; редкол.: В. Г. Шадурский (ред.) [и др.]. Минск: БГУ. 2018. С. 6-12.

6. Киреева A. А. «Инициатива пояса и пути»: содержание, цели и значение // Сравнительная политика. 2018. № 2. С. 61-74.

7. Чубаров И. Г., Калашников Д. Б. «Один пояс - один путь»: глобализация по-китайски // Мировая экономика и международные отношения. 2018. Том 62. № 1. С. 25-33.

8. Nye J. Soft Power: The Means to Success in World Politics. New York: Public Affairs Group. 2004. $191 \mathrm{p}$.

9. Леонова О. Г. Интерпретация понятия «мягкая сила» в науке // Обозреватель. 2015. № 2. C.80-89.

10. 黄令坦.“一带一路”建设亟需发挥文化软实力的先行作用// 宁夏党校学报. 2016. 第 18 卷 第 6 期. 第 80-83 页. = Хуан Линтань. Ведущая роль «мягкой силы»культуры в инициативе «Пояс - путь» // Журнал партийной школы Нинся. 2016. Том 18, №6. С. 80-83.

11. 范周, 周洁. 《一带一路》战略背景下的中国文化软实力建设研究 // 同济大学学报 (社会科 学版). 2016. №5. 第 40-47 页. = Фань, Чж., Чжоу, Цзе. Исследование конструирования китайской мягкой силы культуры в рамках инициативы «Пояс - путь» // Вестник Университета Тунцзи (социальные науки). 2016. № 5. С. 40-47.

Дата поступления статьи: 12.04.2021.

Автор: Чувилов Иван Алексеевич - аспирант кафедры политологии Белорусского государственного экономического университета; e-mail: chuvilovi @mail.ru.

\section{THE BELT AND ROAD INITIATIVE: REASONS FOR PROMOTION AND STRENGTHENING OF THE HUMANITARIAN AREAS OF IMPLEMENTATION}

\author{
I.A. CHUVILOV \\ Belarusian State Economic University, Minsk, Republic of Belarus
}

\begin{abstract}
The present study provides arguments that prove the continuity between the Great Silk Road and the Belt and Road Initiative, examines the role of this initiative in shaping a new political model of the international order. The author argues the importance of the Belt and Road Initiative for the modern foreign policy of China and assesses the prospects for the development of this initiative. The novelty of
\end{abstract}


this work lies in the consideration of the connection between the Great Silk Road, the Belt and Road Initiative, as well as the tributary system of imperial China and the idea of building a community of the common destiny of mankind; introduction into scientific parlance the concept of humanitarian strategies for the implementation of the Belt and Road Initiative. The author comes to the following conclusions:

1) the Belt and Road initiative was a bold attempt by China's foreign policy elites to revive the power of the Chinese state, based on the successful experience of interaction with the international community during the era of the Great Silk Road;

2 ) in the ways of implementing the Belt and Road initiative, along with economic factors and directions, it is necessary to stress out also the humanitarian strategies, which by the end of the second decade of the 21 st century begin to have more important role.

The results of this study can be used for further study of the Belt and Road Initiative, for research from the standpoint of political and historical sciences of the foreign policy of modern China.

Keywords: the People's Republic of China; the Great Silk Road; the Belt-Road Initiative; China's foreign policy; the tributary system; the community of the common destiny of mankind; humanitarian strategies; culture; art; education; Huaqiao.

For citation: Chuvilov I. A. (2021). Initsiativa «Poyas - put'»: prichiny vydvizheniya i aktivizatsiya gumanitarnykh napravleniy realizatsii [The Belt and Road Initiative: reasons for promotion and strengthening of the humanitarian areas of implementation]. In: Actual problems of international relations and global development: collection of scientific papers. Minsk, Vol. 9, p. 276-288. https://doi.org/10.33581/23119470-2021-9-276-288

\section{References}

1. Vestad O. A. (2014). Bespokojnaja imperija. Kitaj i mir s 1750 goda [Restless empire. China and the world since 1750]. Moscow, ZAO Izdatel'stvo Centrpoligraf, 2011. 639 p. (In Russ.).

2. Fairbank J. K., Teng S. Y. (1941). On the Ch'ing Tributary System. In: Harvard Journal of Asiatic Studies. Vol. 6. No. 2, p. 135-246.

3. Xi Jinping. (2018). O gosudarstvennom upravlenii [The Governance of China] Tom 1. Pekin: Izd-vo lit. na inostr. jaz., 654 p. (In Russ.).

4. Zeng Lingliang (2016). Conceptual analysis of China's Belt and Road initiative: a road towards a regional community of common destiny. In: Chinese Journal of international law. Vol. 15. No. 3 , p. 517-541.

5. Bajchorov A. M. (2018). Iniciativa «Odin pojas - odin put'»: strategicheskie i takticheskie zadachi [Belt and Road Initiative: strategic and tactical objectives]. In: Belorussko-rossijskie otnoshenija na sovremennom jetape: sostojanie i perspektivy razvitija: materialy kruglyh stolov. Belorus. gos. un-t ; redkol.: V. G. Shadurskij (pred.) [i dr.]. Minsk: BGU, p. 6-12. (In Russ.).

6. Kireeva A. A. (2018) «Initsiativa poiasa i puti»: soderzhanie, tseli i znachenie [Belt and Road Initiative: Overview, Objectives and Implications]. In: Comparative Politics Russia. No. 2, p. 6174. (In Russ.).

7. Chubarov I. G., Kalashnikov D. B. (2018). «Odin pojas - odin put'»: globalizacija po-kitajski [Belt and Road: globalization in Chinese way] In: World Economy and International Relations. Tom 62. No. 1, p. 25-33. (In Russ.). 
8. Nye J. (2004). Soft Power: The Means to Success in World Politics. New York: Public Affairs Group, $191 \mathrm{p}$.

9. Leonova O. G. (2015). Interpretacija ponjatija «mjagkaja sila» v nauke [Interpretation of the concept of 'soft power' in science] In: The Observer. No. 2, p. 80-89. (In Russ.).

10. 黄令坦 (2016).“一带一路”建设亟需发挥文化软实力的先行作用// 宁夏党校学报. 第 18 卷 第 6 期, 第 80-83 页. = Huan Lintan' (2016). The Leading Role of Cultural Soft Power in the Belt and Road Initiative. In: Journal of Ningxia Communist Party Institute. Vol. 18, № 6, p. 80-83. (In Chin.).

11. 范周, 周洁 (2016). 《一带一路》战略背景下的中国文化软实力建设研究 // 同济大学学报 9 社会科学版). № 5, 第 40-47 页. = Fan' Chzhou, Chzhou Cze (2016). Research on the Construction of Chinese Soft Power of Culture under the Belt and Road Initiative. In: Journal of Tongji University (social science section). No. 5, p. 40-47. (In Chin.).

Received: 12.04 .2021 .

About author: Chuvilov Ivan Alekseevich - post-graduate student of the Department of Political Science, BSEU; e-mail: chuvilovi@mail.ru. 